\title{
Study on Rules for Spiral Groove of Swirl Nozzle to Performance of Inside Flow
}

\author{
Yong Guo ${ }^{1, *}$, Lili Guo ${ }^{2}$ and Longyan Zhang ${ }^{3}$ \\ ${ }^{1}$ Hunan University of science and technology, HuNan Xiangtan, 411100, China \\ ${ }^{2}$ Hunan Bilv EP industry development Co.,LTD, HuNan Xiangtan, 411100,China \\ * Corresponding author
}

\begin{abstract}
With the advantages of convenient processing, easy control for geometry size and adjustable parameters, single head spiral groove nozzle is widely applied in the field of environmental protection equipment. According to the lackage of rules on structure parameters of spiral groove to spray performance and supply power, spiral slot geometric model was set up, and three dimension numerical analysis was carried on using k- $\varepsilon$ predominate turbulence model by fluent. The rules of spiral slot length, spiral groove depth, and groove pitch to flow velocity increasing ratio and frictional pressure loss were acquired. It supplies a theoretical guidance and basis for design of spiral groove of swirl nozzle.
\end{abstract}

Keywords—nozzle; spiral groove; velocity increasing ratio; pressure loss component

\section{INTRODUCTION}

The small particles generated by swirl atomizing nozzle are more stable. It can make cleaning effect of dust and industrial waste gas better with the increasing of the effective contact area of air purification. Owing to this virtue, it is a key component widely used in the field of environmental protection equipment, such as spray scrubber, flue gas desulphurization equipment, spray atomization device. The atomization effect of the swirling nozzle is enhanced by the speed increase with spiral structure. The main structure has two kinds [1-2]. One is done by setting a pipe with different angles of incidence, and the other is to set a spiral groove on the pipe. It is difficult to process and control the structure size by setting the swirling flow of the pipes with different incidence angles [3]. Spiral grooves on pipelines are easy to process. The geometric structure and size of spiral grooves are easy to control with some parameters easily adjustable, so that atomizing effect can be adjusted within a certain range. Therefore, the spiral groove structure of pipes has been widely applied in nozzles [4].

The geometric parameters of spiral groove directly affect the effect of speed increasing and the pressure loss along the pipeline, and can cause a change of water atomization degree and increase of the power supply of the water supply unit. Most of the existing studies on spiral grooved tubes are focused on heat transfer and resistance characteristics in a single tube with spiral grooved tubes [5-6]. The influence rules of structural parameters on heat transfer coefficient and drag coefficient are analyzed through the flow field analysis of pipe fluid. According to the spray performance requirements of the nozzle, the study on the effect of the spiral groove structure on the effect of speed increasing and the pressure loss along the pipeline is still very short.

In this paper, a swirl spray nozzle with a spiral groove is proposed, and an analytical model of the flow field for spiral groove using the finite volume method is established. The influence law of spiral groove length, depth and slot to the effect of speed increasing and the pressure loss along the pipeline is acquired, which provide theoretical guidance and a basis for the design of a spiral groove spiral swirl nozzle.

\section{PHySICAL MOdEL OF FLOW FIELd ANALYSIS OF} Single HeAD SPIRAL GROOVE OF SWIRLING NOZZLE

The common spiral groove swirling nozzle structure, as shown in Figure I, is made up of a spiral speed increase catheter, a pitch nut, a locking nut and a nozzle. The water flows through the spiral tube growth by damping holes evenly distributed. The first time of atomization occurs in the cavity spiral growth.Then, the water flows through the valve nozzle and spiral growth between the nozzle and orifice catheter for second time atomization. The water atomization performance is enhanced by double atomization. At the same time, the adjustment of the pitch nut can change the ejection distance.

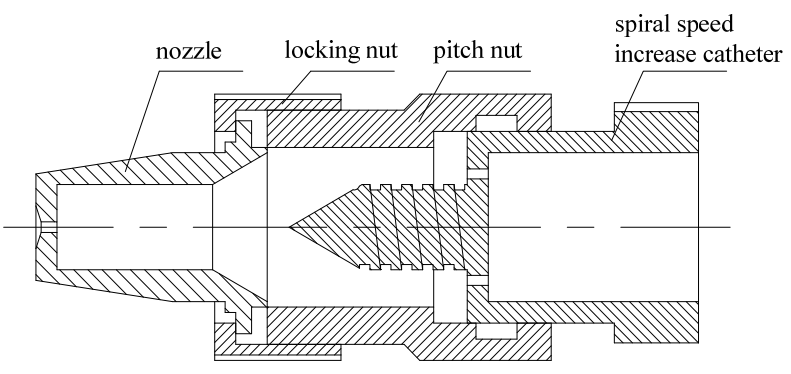

FIGURE I. SWIRLING NOZZLES WITH SPIRAL GROOVE

The spiral groove tube formed by spiral speed increase catheter and the pitch nut makes the flow speed increase, which is the guarantee of the atomization effect. The fluid pipe formed by the two components is represented by the spiral groove tube illustrated in Figure II. In the picture, the inner diameter of the spiral groove tube is $8 \mathrm{~mm}$, the outer diameter is $15 \mathrm{~mm}$, the effective spiral distance is $10 \mathrm{~mm}$, the pitch is $2 \mathrm{~mm}$, and the spiral groove depth is $1 \mathrm{~mm}$. 


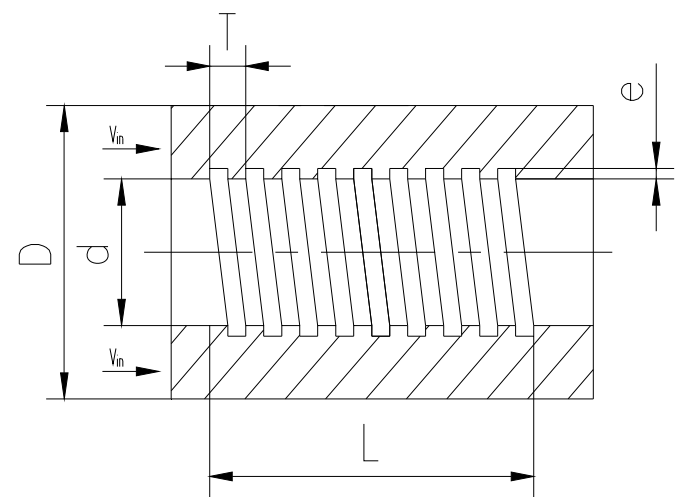

FIGURE II. FLOW FIELD MODEL OF SINGLE HEAD SPIRAL GROOVE OF SWIRLING NOZZLE

\section{Establishment OF CFd Simulation Model For SPIRAL GROOVE}

A three-dimensional model of a spiral groove tube is established using Gambit. The flow field is divided into two parts. One is the pipe fluid, and the other is the trough fluid. The inner surface of the fluid in the trough is meshed by nonstructural grid, and the hexahedral grid is used in fluid meshing. The fluid in the pipe is meshed by tetrahedral grid. The division of the fluid grid in the spiral groove is shown in Figure III. with hexahedral mesh in the surface area, and the rest with tetrahedral mesh, and the number of initialization grids is 9553 .

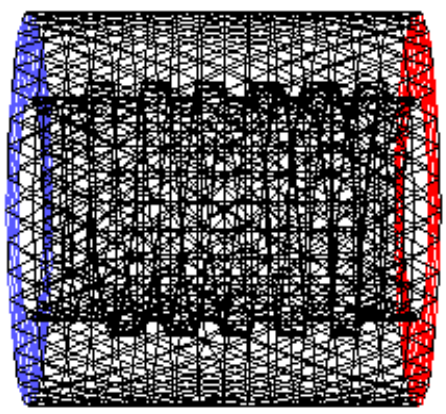

FIGURE III. MESH MODEL OF FLUID IN SPIRAL GROOVE

The boundary conditions of the calculated area are set according to the actual conditions as follows. The spiral conduit at the inlet of the nozzle is provided by the water pump for the velocity entrance boundary. According to the definition of various parameters in Fluent, the inlet speed of swirl nozzle spiral groove is $1 \mathrm{~m} / \mathrm{s}$. The turbulence intensity is $1 \%$, and the hydraulic diameter is $8 \mathrm{~mm}$. The outlet of the spiral groove is the pressure outflow boundary. The turbulence intensity is $1 \%$, and the hydraulic diameter is $8 \mathrm{~mm}$. The rest of the surface is set to the wall, and the default settings are reserved.

A separate solver is set up in Fluent to solve the problem. The flow field in the spiral groove is a turbulence model. The Realize k- e model is adopted, the wave parameter Ce2is set to 1.9, the turbulent Prandtl number is set to 1 , the TDR Prandtl number is set to 1.2 , and the energy Prandtl number is set to 0.85 . After the above parameters are set in Fluent, the initialization iteration calculation is carried out. The convergence of the calculation is judged through the residual curve.If the residual difference reaches 10-6, it can be considered to be convergent. At the same time, the entry and exit quality monitoring curves are set up to monitor the convergence process of the equations solution. The relevant settings are adjusted according to the problems until the specified convergence accuracy is achieved. The simulation carried on 100 times, and the residual curve is shown in Figure IV. The residual curve fluctuation remains unchanged after iteration of 72 times, and the residuals of all indexes are all below 10-6.
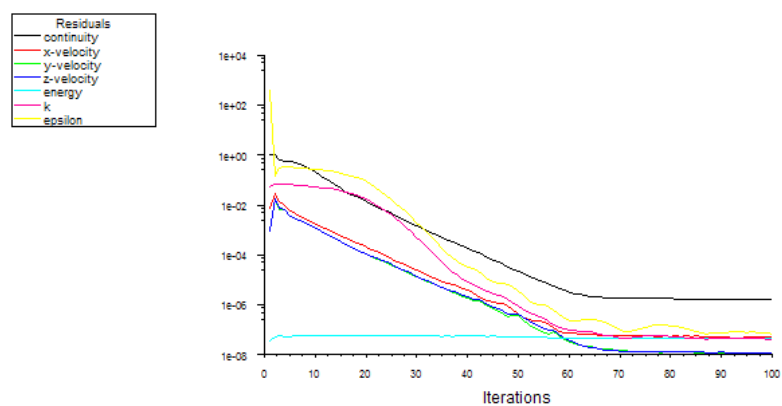

FIGURE IV. RESIDUAL MONITORING CURVE OF CALCULATION AND ANALYSIS

\section{Simulation RESUlts}

The velocity curve at the center section obtained by simulation is shown in Figure V, and the pressure curve at the center section is shown in Figure VI. As you can see, the average pressure at the exit is $0.18 \mathrm{Mpa}$, and the average speed at the exit is $1.128 \mathrm{~m} / \mathrm{s}$, which increase by 0.13 time of the entrance. The pressure loss from the entrance to the exit is $0.08 \mathrm{Mpa}$. Therefore, the setting of the spiral groove can increase the flow velocity of the fluid to improve the effect of fluid atomization, but it also increases the pressure loss at the same time.
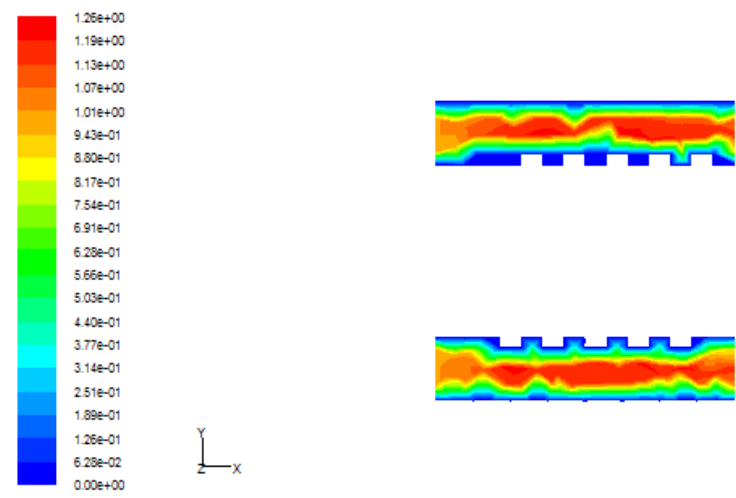

FIGURE V. VELOCITY DISTRIBUTION CLOUD MAP IN CENTER SECTION OF SPIRAL GROOVE TUBE 

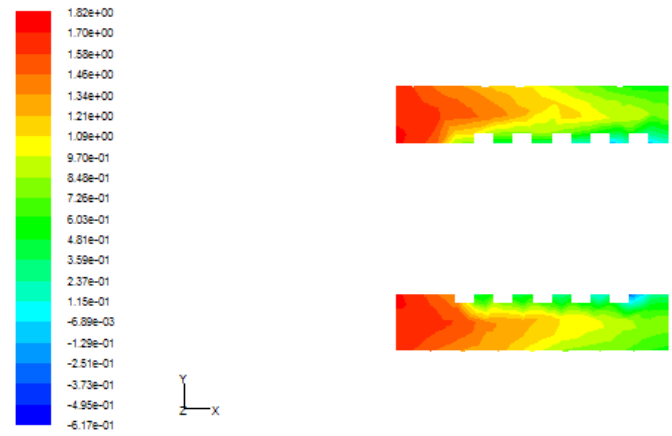

FIGURE VI. PRESSURE DISTRIBUTION CLOUD MAP IN CENTER SECTION OF SPIRAL GROOVE TUBE

The length of the spiral groove, groove depth and spiral slot structure parameters has a great effect on speed increasing and pressure loss. The length of the spiral groove is changed. $\mathrm{L}=8 \mathrm{~mm}, 10 \mathrm{~mm}$ and $12 \mathrm{~mm}$ are taken respectively. The average velocity curve of the spiral groove pipe section is obtained by taking the ratio of spiral groove length to inner diameter ratio as the research object, as shown in Figure VII (a). The average pressure curve of spiral groove pipe section is shown in Figure VII (b). Figure VII shows that when the ratio of the length of the spiral groove to the inner diameter is 1.25 , the speed-up effect is the most significant and the speedup ratio reaches to 1.09 . Therefore, the ratio of the spiral groove length to the inner diameter value should be chosen within the range of $1 \sim 1.5$ in order to make the speedup ratio approach to the maximum. At the same time, the greater the value of the alpha, the higher the pressure loss produced by the spiral groove. But when alpha is $1 \sim 1.5$, the pressure loss is less than $0.09 \mathrm{Mpa}$. Therefore, when the alpha is in the $1 \sim 1.5$ range, the pressure loss produced by the spiral groove is very small, which can be ignored.

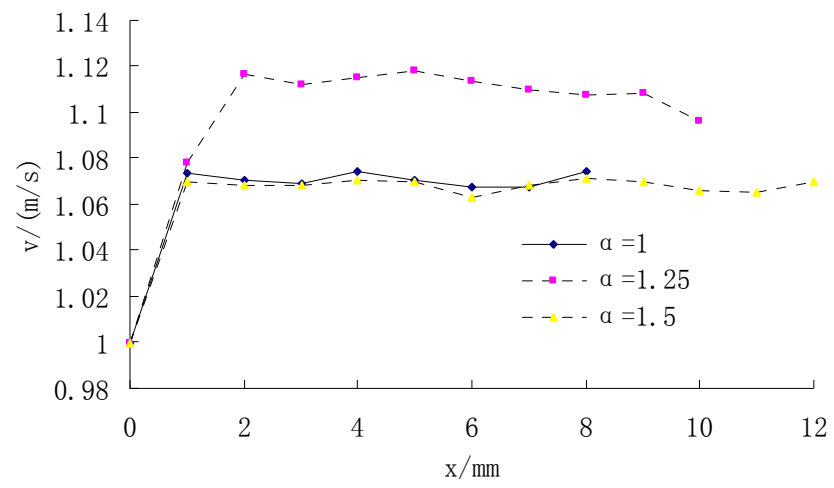

(a) Average velocity of cross section of spiral groove tube

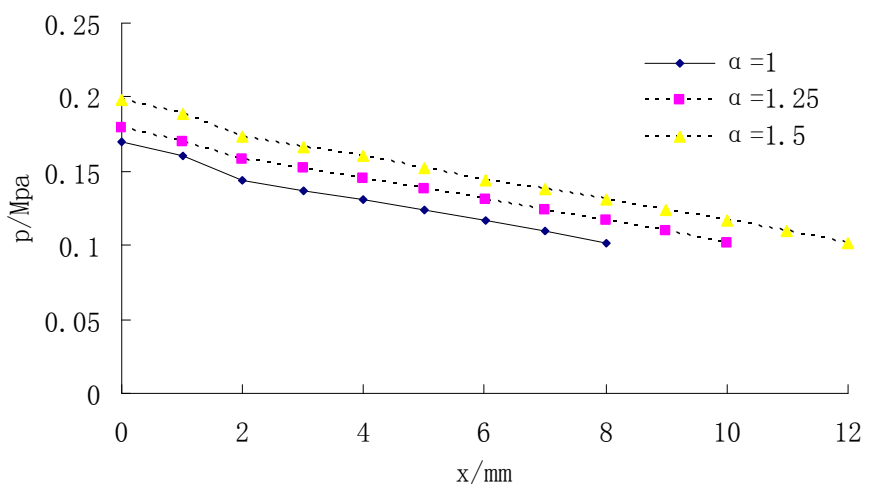

(b) Average pressure of cross section of spiral groove tube

\section{FIGURE VII. EFFECT OF ATO FLOW VELOCITY AND PRESSURE IN SPIRAL GROOVED TUBE}

The spiral slot of spiral groove is changed. $\mathrm{T}=1 \mathrm{~mm}, 2 \mathrm{~mm}$ and $3 \mathrm{~mm}$ are taken respectively. The average velocity curve of spiral groove pipe section is obtained by taking the ratio of slot to inner diameter as the research object, as shown in Figure VIII (a). The average pressure curve of spiral groove pipe section is shown in Figure VIII (b). Figure VIII shows that the speed-up effect is the most significant when the ratio of slot to inner diameter is 0.25 . At the same time, when the value of the ratio for slot and the inner diameter is 0.25 , the pressure loss of the spiral groove is the least, only $0.06 \mathrm{MPa}$.

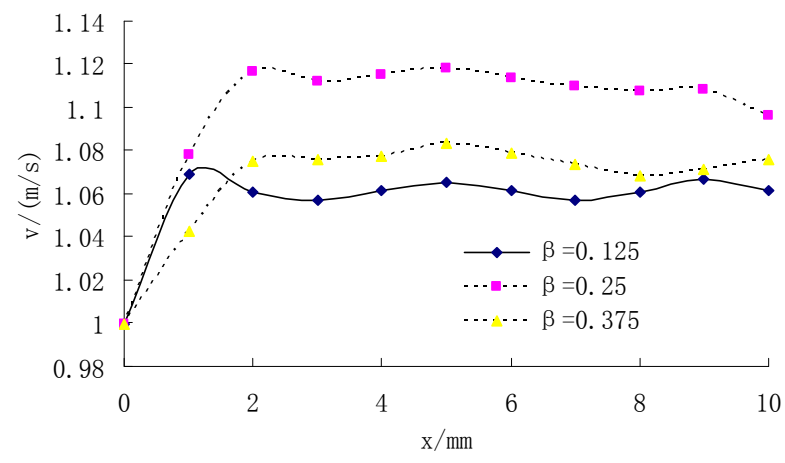

(a) Average velocity of cross section of spiral groove tube

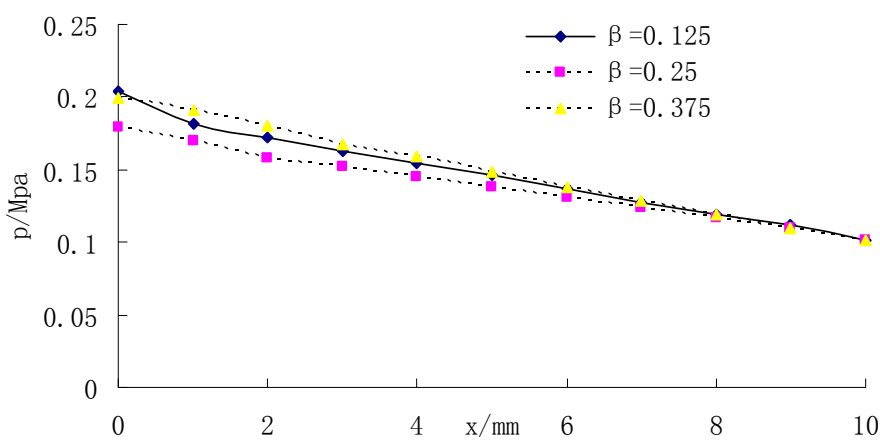

(b) Average pressure of cross section of spiral groove tube

FIGURE VIII. EFFECT OF $\beta$ TO FLOW VELOCITY AND PRESSURE IN SPIRAL GROOVED TUBE 
The depth of spiral grooves is changed. $\mathrm{e}=0.5 \mathrm{~mm}, 1 \mathrm{~mm}$ and $1.5 \mathrm{~mm}$ are taken respectively. The ratio for depth of spiral groove to inner diameter is taken as the research object, and the average velocity curve of spiral groove section is obtained, which is shown in Figure IX (a). The average pressure curve of spiral groove section is shown in Figure IX (b). Figure IX shows that the speed-up effect is more significant when the ratio for depth of spiral groove to inner diameter increases. However, the pressure loss also increases with the increase of the ratio for depth of spiral groove to inner diameter, and the effect is very small when the ratio is in the range of $0.0625 \sim 0.125$.

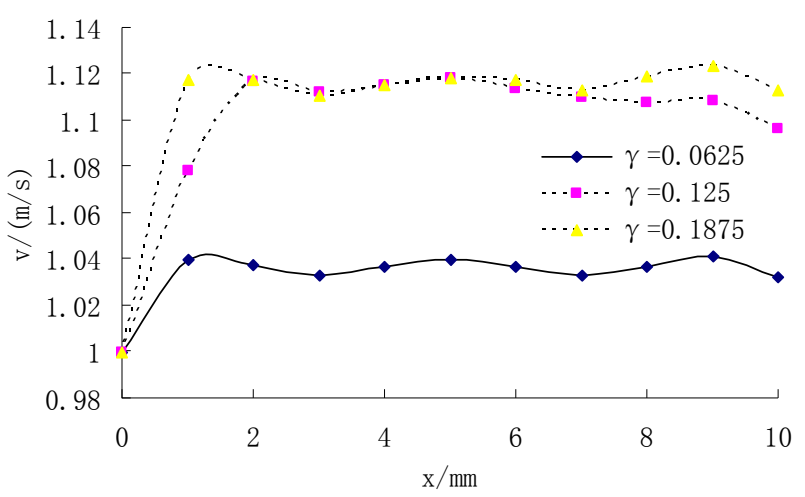

(a) Average velocity of cross section of spiral groove tube

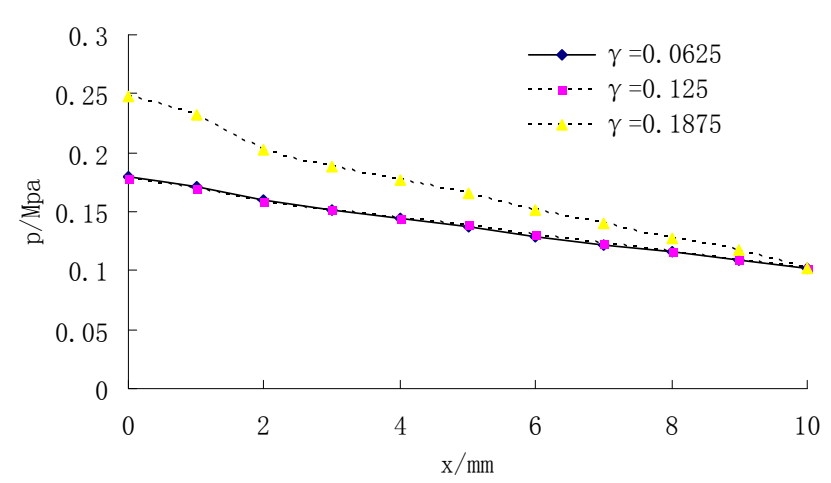

(b) Average pressure of cro

FIGURE IX. EFFECT OF TTO FLOW VELOCITY AND PRESSURE IN SPIRAL GROOVED TUBE

\section{CONCLUSION}

The setting of the spiral groove has an obvious effect on the speed-up effect of the fluid, and also increases the pressure loss along the path. In order to acquire the maximum speed-up effect of the fluid, the ratio of spiral groove length to inner diameter should be chosen in the range of $1 \sim 1.5$, the ratio for slot of spiral groove to inner diameter should be chosen in $0.125 \sim 0.375$, and the ratio for depth of spiral groove to the inner diameter should be chosen as large as possible. The increase of the ratio for length of spiral groove to the inner diameter and the ratio for depth of spiral groove to inner diameter causes the increase of the pressure loss. However, the effect to pressure loss is very small when the ratio is in the range of $0.0625 \sim 0.125$. When the value of the ratio for the slot and the inner diameter is 0.25 , the pressure loss of the spiral groove is the least.

\section{ACKNOWLEDGEMENT}

This research was financially supported by the National Science Foundation 51705147, and Hunan Provincial Education Department Project 15C0542.

\section{REFERENCES}

[1] L.J. Wang, D.W. Sun, P. Liang, et al. Heat transfer characteristics of carbon steel spirally fluted tube for high pressure pre heaters, Energy Conversion and Management. 41( 2000) 993-1005.

[2] D.P. Liu, S.D. Li. Contrast experiment of the spray characteristics of four atomizing nozzle, Fluid Machinery. 41(2013)1-6.

[3] L.Q. Wang, S.D. Lin, Y.L. Tian, et al. Study on great flow nozzle performance with CFD method, Fluid Machinery. 36(2008)17-23.

[4] M.Z. Li, G.R. Zhao. High pressure spray nozzle design and parameter optimization based on finite element simulation analysis, Journal of China Coal Society.40 (2015)509-514.

[5] P.G. Vicente, A. Garcia, A. Viedma. Experimental investigation on heat transfer and frictional characteristics of spirally corrugated tubes in turbulent flow at different Prenatal number, International Journal of Heat and Mass Transfer. 47(2000) 671-681.

[6] Y.H. Wang, N. Sun, K.T. Gui. Numerical simulation of the convection-based heat exchange characteristics outside spirally grooved tube bundles, Journal of Engineering for Thermal and Power.29 (2014)509-514. 